\title{
Toxicological Evaluation of Disulfiram, Copper Gluconate and Disulfiram/Copper Gluconate Combination on Renal Function in Rodents
}

\author{
Udeme Owunari Georgewill, Iyeopu Minakiri Siminialayi, \\ Atuboyedia Wolfe Obianime \\ Department of Pharmacology, Faculty of Basic Medical Sciences, College of Health Sciences, University of Port \\ Harcourt, Port Harcourt, Nigeria \\ Email: udgeorgewill@yahoo.com
}

Received 5 December 2014; accepted 8 February 2015; published 10 February 2015

Copyright (C) 2015 by authors and Scientific Research Publishing Inc.

This work is licensed under the Creative Commons Attribution International License (CC BY). http://creativecommons.org/licenses/by/4.0/

\section{(c) (i) Open Access}

\section{Abstract}

This research work investigated and compared the chronic renal toxicological profile of disulfiram, copper gluconate and disulfiram/copper gluconate combination, in a 90-day time- and dose-dependent study in rodents. 88 rats weighing an average of $280 \mathrm{~g}$ divided into eleven groups consisting of 8 rats each were used for this experiment. The control groups received normal saline as placebo and $\mathbf{9 9 . 5 \%}$ dimethyl sulfoxide (DMSO) (solvent control). Three oral doses (low, medium and high) of disulfiram $(18.65 \mathrm{mg} / \mathrm{kg}, 37.3 \mathrm{mg} / \mathrm{kg}$ and $74.6 \mathrm{mg} / \mathrm{kg})$, copper gluconate $(3.75 \mathrm{mg} / \mathrm{kg}$, $7.5 \mathrm{mg} / \mathrm{kg}$ and $15 \mathrm{mg} / \mathrm{kg}$ ) and both drugs in combination were administered daily with those of the combination given 12 hours apart. Blood samples were collected via cardiac puncture in heparinised bottles and centrifuged, and the serum was decanted on 30, 45, 60 and 90 days for analysis. Renal function parameters-electrolytes $\left(\mathrm{Na}^{+}, \mathrm{K}^{+}\right)$, urea and creatinine were evaluated. Results showed significant $(\mathrm{p}<0.05)$ dose- and time-dependent increase in electrolyte level $\left(\mathrm{Na}^{+}\right.$, $\mathrm{K}^{+}$), blood urea and creatinine respectively. The results are all pointers to the development of renal failure. It therefore appears that the DSF/CG combination is nephrotoxic and this effect is dose-dependent and synergistic.

\section{Keywords}

Disulfiram, Copper Gluconate, Renal Function 


\section{Introduction}

Cancer, also termed malignant tumour or neoplasm, is a group of diseases involving abnormal cell growth with a potential to invade or spread to other parts of the body. In Nigeria, breast cancer, cervical cancer and prostate cancer are most prevalent amongst women and men respectively [1]. Added to this, is the burden cancer imposes on the Niger delta region of Nigeria where this study is sited. Researchers attest to the fact that individuals in this region are at increasing risk of developing cancers as a result of oil exploration activities [2]. This underscores the interest of the researchers in new drug treatment for cancers that would be readily available to low-income economies and affordable. Disulfiram is an old drug hitherto used for alcoholism. The addition of copper gluconate makes the combination a potentially effective and cheap means of treating cancer and is therefore being repurposed for use in cancer chemotherapy. Repurposing non-cancer related drugs with possible anti-tumoral activities is a promising strategy for identifying prospective new anti-cancer drugs in a cost-efficient and timesaving way [3]-[5]. Repurposing disulfiram has recently become of interest because of its pre-clinically described anti-cancer effects against various human cancers, which include breast, cervical, colorectal, lung, melanoma, prostate as well as myeloma and leukaemia [6] [7]. Disulfiram, a member of the dithiocarbamate family, possesses metal-binding properties [8] and is thought to inhibit superoxide dismutase resulting in inhibition of the angiogenic potential [9]. In the presence of $\mathrm{Cu}$ (II), disulfiram is converted to the two-electron oxidized form of diethyldithiocarbamate, which is the active form in inducing cell death [10]. Chen et al. [11] have reported that disulfiram could bind to cellular copper or zinc to form a complex that has a proteasome-inhibitory effect, which might contribute to its apoptosis-inducing effect. Diethyldithiocarbamate is a main physiological metabolite found after gastrointestinal uptake of disulfiram [12]-[14]. Disulfiram and diethyldithiocarbamate are convertible into each other via a copper containing intermediate complex. Cen et al. [10] also proposed that the complex of two diethyldithiocarbamate molecules formed by redox active $\mathrm{Cu}$ (II), could be mainly responsible for the proapoptotic response to disulfiram. In a study on ovarian cancer cell lines, Papaioannou et al. [15] reported that when cell lines were tested using disulfiram alone and disulfiram with copper supplementation, disulfiram alone reduced cell survival of ovarian cancer cells at an optimum concentration even in the absence of copper supplementation, but supplementation with $1 \mu \mathrm{M}$ copper chloride, increased the cytotoxic effect of disulfiram in all other ovarian cancer cells tested.

A major problem with most antineoplastic agents is the adverse effects that occur following their use. Renal failure in cancer patients is a common problem in oncology and this complication is frequently multifactorial in origin. Several antineoplastic agents are potentially nephrotoxic; previous renal impairment as well as combinations with other nephrotoxic drugs may increase the risk of nephrotoxicity during administration of chemotherapy [16]. Also, exposure to heavy metals is potentially harmful. Because of its ability to reabsorb and accumulate divalent metals, the kidney is the first target organ of heavy metal toxicity. The extent of renal damage by heavy metals depends on the nature, the dose, the route and the duration of exposure [17]. We set out to study the effect of disulfiram, copper gluconate and disulfiram/copper gluconate combination on the kidneys in rodents.

\section{Methodology}

88 male albino Swiss rats weighing an average of $280 \mathrm{~g}$ obtained from the Department of Pharmacology animal house were used for this study. The rats were bred and maintained under suitable conditions, allowed an acclimatization period of two (2) weeks, housed in hygienic cages in groups of four and allowed free access to feed obtained from vital feeds UAC PLC and water ad libitum. The beddings were changed and cages cleaned out on alternate days. Animals were handled according to Helsinki declaration on animal care. The animals were divided into 11 groups, each consisting of 8 rats each. The groups included those for treatment and the control groups. Drugs were administered orally via a $1 \mathrm{ml}$ syringe.

\section{Chronic Toxicity Tests}

This study spanned 3 months and was domiciled in the Department of Pharmacology, University of Port Harcourt, Animal House and Laboratory. A dose and time dependent toxicological evaluation of the effects of these individual drugs and their combinations on the renal profiles of rodents was evaluated. The rats were divided into eleven groups consisting of 8 rats each. Groups 1 and 2 served as control groups and the rats received normal saline as placebo and 99.5\% DMSO (solvent control) respectively. Drugs were administered orally via a 1 $\mathrm{ml}$ syringe as $1 / 5^{\text {th }}, 1 / 10^{\text {th }}$ and $1 / 20^{\text {th }}$ of the $\mathrm{LD}_{50}$ of disulfiram and copper gluconate at $373 \mathrm{mg} / \mathrm{kg}$ and $75 \mathrm{mg} / \mathrm{kg}$ respectively [18]. 


\section{Drug Administration}

Control group 1: Had 8 rats and received $1 \mathrm{ml}$ of normal saline orally daily;

Control group 2/Solvent control: Had 8 rats and received $0.5 \mathrm{ml}$ of (DMSO) dimethyl sulfoxide;

Group 3a: Had 8 rats and received $15 \mathrm{mg} / \mathrm{kg}$ of copper gluconate daily orally;

Group 3b: Had 8 rats and received $7.5 \mathrm{mg} / \mathrm{kg}$ of copper gluconate daily orally;

Group 3c: Had 8 rats and received $3.75 \mathrm{mg} / \mathrm{kg}$ of copper gluconate daily orally;

Group 4a: Had 8 rats and received $74.6 \mathrm{mg} / \mathrm{kg}$ of DSF and $15 \mathrm{mg} / \mathrm{kg}$ of copper gluconate daily orally;

Group 4b: Had 8 rats and received $37.3 \mathrm{mg} / \mathrm{kg}$ of DSF and $7.5 \mathrm{mg} / \mathrm{kg}$ of copper gluconate daily orally;

Group 4c: Had 8 rats and received $18.65 \mathrm{mg} / \mathrm{kg}$ of DSF and $3.75 \mathrm{mg} / \mathrm{kg}$ of copper gluconate daily orally;

N/B The drug combination was given following the protocol of Grossman et al. [19];

Group 5a: Had 8 rats and received $74.6 \mathrm{mg} / \mathrm{kg}$ of DSF daily orally;

Group 5b: Had 8 rats and received $37.3 \mathrm{mg} / \mathrm{kg}$ of DSF daily orally;

Group 5c: Had 8 rats and received $18.65 \mathrm{mg} / \mathrm{kg}$ of DSF daily orally.

\section{Collection of Samples}

Two animals per group were sacrificed using diethyl ether anaesthesia and blood samples were obtained on days 30, 45, 60 and 90 for analysis via cardiac puncture. Blood samples were centrifuged at $3000 \mathrm{rpm}$ for 15 minutes and serum separated from the cells. The samples were then assayed for $\mathrm{Na}^{+}, \mathrm{K}^{+}$, by flame photometry [20] and urea and creatinine using the Clinical Chemistry Autoanalyser RX Series by Randox Laboratories Limited, United Kingdom.

\section{Stock Solutions}

Stock solutions were prepared from 99.5\% DMSO for disulfiram and distilled water for copper gluconate. Pure analytical grade samples, CAS No. 527-09-3 (98\% min purity) and CAS No. 97-77-8 (98\% min purity) obtained from Shijiazhuang Aopharm Import and Export Co. Limited China were used for the study.

\section{Ethical Approval}

Ethical approval was obtained from the University of Port Harcourt Research Ethics Committee.

\section{Statistical Analysis}

Statistical analysis was done using graph pad prism 5 statistical package and ANOVA for comparison of the means of the various groups. Results are expressed as means \pm SEM. Test group results were compared with that of the control groups. A p-value $<0.05$ was considered significant.

\section{Results and Discussion}

Anticancer agents are frequently associated with a variety of renal and electrolyte disorders. These drugs could affect the kidneys manifesting as an asymptomatic elevation of serum creatinine or acute renal failure. The kidneys are the major pathway for elimination of many antineoplastic agents as well as their metabolites. Therefore, renal impairment can result in delayed drug excretion and metabolism of anticancer agents resulting to increased systemic toxicity. Potassium, an essential intracellular, positively charged ion, is actively "pumped" in to the cell from surrounding extracellular fluid, while, sodium, is pumped out. This is necessary for proper fluid balance, and creates an electrical charge across the cell membrane. This is also the fundamental principle which allows nerves to conduct impulses and so communicate between cells and muscles to contract. Potassium is important to proper heart functioning. Hypokalaemia or hyperkalaemia quickly leads to electrolyte imbalance which affects all muscles, nerves and numerous key body functions. Increased potassium levels could be as a result of damage to the kidneys resulting in extrusion of the ions into the extracellular space [21]. Results of the present study revealed that low dose disulfiram, copper gluconate and disulfiram/copper gluconate combination revealed significantly increased $(\mathrm{p}<0.05)$ sodium ion levels (Table 1$)$. Medium and high doses of all three therapeutic agents significantly increased $(\mathrm{p}<0.05)$ sodium levels (Table 2 and Table 3). Low, medium and high doses of 
Table 1. Effect of low dose DSF (18.65 mg/kg), CG (3.75 mg/kg) and DSF/CG (18.65/3.75 mg/kg) on Na ${ }^{+}(\mathrm{mEq} / \mathrm{l})$.

\begin{tabular}{ccccc}
\hline & 30 Days & 45 Days & 60 Days & 90 Days \\
\hline CONTROL 1 & $146.7 \pm 0.882$ & $145.3 \pm 2.667$ & $142.0 \pm 1.528$ & $143.7 \pm 0.882$ \\
DSF & $151.3 \pm 0.333^{*}$ & $156.3 \pm 1.202^{*}$ & $153.0 \pm 1.000^{*}$ & $153.7 \pm 1.856^{*}$ \\
CG & $154.3 \pm 0.333^{*}$ & $155.3 \pm 1.333^{*}$ & $155.7 \pm 1.202^{*}$ & $157.0 \pm 1.000^{*}$ \\
DSF/CG & $157.0 \pm 0.577^{*}$ & $157.7 \pm 0.333^{*}$ & $158.3 \pm 0.333^{*}$ & $158.7 \pm 0.333^{*}$ \\
\hline
\end{tabular}

Results are expressed as mean \pm SEM, the superscript $(*)$ means significant difference with respect to control at $\mathrm{p}<0.05$ (ANOVA).

Table 2. Effect of medium dose DSF (37.3 mg/kg), CG (7.5 mg/kg) and DSF/CG (37.3/7.5 mg/kg) combination on Na $(\mathrm{mEq} / \mathrm{l})$.

\begin{tabular}{|c|c|c|c|c|}
\hline & 30 Days & 45 Days & 60 Days & 90 Days \\
\hline CONTROL 1 & $144.3 \pm 2.186$ & $144.3 \pm 2.186$ & $145.7 \pm 2.603$ & $146.3 \pm 2.186$ \\
\hline DSF & $155.0 \pm 1.528 *$ & $155.7 \pm 0.882^{*}$ & $156.0 \pm 2.309^{*}$ & $156.3 \pm 2.333^{*}$ \\
\hline CG & $158.3 \pm 1.202^{*}$ & $160.3 \pm 0.882^{*}$ & $158.7 \pm 1.453^{*}$ & $159.3 \pm 1.202 *$ \\
\hline $\mathrm{DSF} / \mathrm{CG}$ & $160.0 \pm 0.577^{*}$ & $160.7 \pm 1.202 *$ & $160.3 \pm 0.882 *$ & $161.3 \pm 0.333^{*}$ \\
\hline
\end{tabular}

Results are expressed as mean \pm SEM, the superscript $(*)$ means significant difference with respect to control at $\mathrm{p}<0.05$ (ANOVA).

Table 3. Effect of high dose DSF (74.6 mg/kg), CG (15 mg/kg) and DSF/CG (74.6/15 mg/kg) combination on $\mathrm{Na}^{+}(\mathrm{mEq} / \mathrm{l})$.

\begin{tabular}{|c|c|c|c|c|}
\hline & 30 Days & 45 Days & 60 Days & 90 Days \\
\hline CONTROL 1 & $146.3 \pm 3.180$ & $160.3 \pm 1.202$ & $146.3 \pm 3.180$ & $146.3 \pm 3.180$ \\
\hline DSF & $164.0 \pm 2.309 *$ & $160.3 \pm 1.202^{*}$ & $162.0 \pm 1.155^{*}$ & $164.0 \pm 2.309 *$ \\
\hline CG & $165.3 \pm 1.764^{*}$ & $162.7 \pm 0.667^{*}$ & $162.7 \pm 0.667^{*}$ & $165.3 \pm 1.764^{*}$ \\
\hline $\mathrm{DSF} / \mathrm{CG}$ & $169.0 \pm 2.082 *$ & $163.3 \pm 0.333^{*}$ & $163.3 \pm 0.333^{*}$ & $169.0 \pm 2.082 *$ \\
\hline
\end{tabular}

Results are expressed as mean \pm SEM, the superscript $(*)$ means significant difference with respect to control at $\mathrm{p}<0.05$ (ANOVA).

all three therapeutic agents increased potassium levels significantly $(\mathrm{p}<0.05)$ (Tables 4-6). This results point to an increased risk for the development of kidney failure perhaps due to direct toxic effects of the agents on the kidneys.

The blood urea nitrogen (BUN) test is a measure of the amount of nitrogen in the blood that comes from urea. It is used as a marker of renal function, though it is inferior to other markers such as creatinine because blood urea levels are influenced by other factors such as diet and dehydration [22]. On urea levels, disulfiram at low dose showed no significant effect ( $p>0.05$ ) while copper gluconate and the disulfiram and copper gluconate combination caused a significant increase $(\mathrm{p}<0.05)$ when compared to the control (Table 7). At the medium and high doses, our results revealed significant increase $(\mathrm{p}<0.05)$ for disulfiram alone, copper gluconate alone and the disulfiram and copper gluconate combination when compared with the control (Table 8 and Table 9).

Effect of low, medium and high dose disulfiram, copper gluconate and their combination on creatinine levels were significantly increased $(\mathrm{p}<0.05$ ) when compared with the control (Tables 10-12). Serum creatinine is an important indicator of renal health because it is an easily measured by-product of muscle metabolism that is excreted unchanged by the kidneys. Plasma creatinine concentration is the most widely used measure for estimation of the glomerular filtration rate (GFR) [23]. Creatinine is synthesized primarily in the liver from the methylation of glycocyamine (guanidino acetate, synthesized in the kidney from the amino acids arginine and glycine) by S-adenosyl methionine and is removed from the blood chiefly by the kidneys, via glomerular filtration and proximal tubular secretion. A rise in blood creatinine level is observed only with marked damage to functioning nephrons. A persistent rise in both urea and creatinine is a sign of kidney failure. Kidney failure and death can occur with as little as 1 gram of copper sulphate [24]. Heavy metals such as cadmium (Cd), mercury (Hg), lead 
Table 4. Effect of low dose DSF (18.65 mg/kg), CG (3.5 mg/kg) and DSF/CG (18.65/3.75 mg/kg) combination on $\mathrm{K}^{+}$ $(\mathrm{mEq} / \mathrm{l})$.

\begin{tabular}{ccccc}
\hline & 30 Days & 45 Days & 60 Days & \\
\hline CONTROL 1 & $4.433 \pm 0.667$ & $4.800 \pm 0.404$ & $4.833 \pm 0.203$ & $4.833 \pm 0.167$ \\
DSF & $5.810 \pm 0.021^{*}$ & $5.993 \pm 0.121^{*}$ & $5.877 \pm 0.065^{*}$ & $5.877 \pm 0.065^{*}$ \\
CG & $6.167 \pm 0.088^{*}$ & $6.233 \pm 0.145^{*}$ & $6.233 \pm 0.145^{*}$ & $6.500 \pm 0.289^{*}$ \\
DSF/CG & $6.340 \pm 0.170^{*}$ & $6.387 \pm 0.199^{*}$ & $6.500 \pm 0.289^{*}$ & $6.900 \pm 0.208^{*}$ \\
\hline
\end{tabular}

Results are expressed as mean \pm SEM, the superscript $(*)$ means significant difference with respect to control at $\mathrm{p}<0.05$ (ANOVA).

Table 5. Effect of medium dose DSF (37.3 mg/kg), CG (7.5 mg/kg), DSF/CG (37.3/7.5 mg/kg) combination on K+ (mEq/l).

\begin{tabular}{ccccc}
\hline & 30 Days & 45 Days & 60 Days & 90 Days \\
\hline CONTROL 1 & $5.100 \pm 0.322$ & $5.100 \pm 0.322$ & $5.033 \pm 0.384$ & $5.100 \pm 0.306$ \\
DSF & $6.610 \pm 0.427^{*}$ & $6.100 \pm 0.126^{*}$ & $6.200 \pm 0.116^{*}$ & $6.200 \pm 0.058^{*}$ \\
CG & $6.767 \pm 0.145^{*}$ & $6.867 \pm 0.186^{*}$ & $7.067 \pm 0.176^{*}$ & $7.133 \pm 0.176^{*}$ \\
DSF/CG & $7.033 \pm 0.273^{*}$ & $7.100 \pm 0.300^{*}$ & $7.133 \pm 0.318^{*}$ & $7.300 \pm 0.153^{*}$ \\
\hline
\end{tabular}

Results are expressed as mean \pm SEM, the superscript $(*)$ means significant difference with respect to control at $\mathrm{p}<0.05$ (ANOVA).

Table 6. Effect of high dose DSF (74.6 mg/kg), CG (15 mg/kg) and DSF/CG (74.6/15 mg/kg) combination on $\mathrm{K}^{+}(\mathrm{mEq} / \mathrm{l})$.

\begin{tabular}{|c|c|c|c|c|}
\hline & 30 Days & 45 Days & 60 Days & 90 Days \\
\hline CONTROL 1 & $5.200 \pm 0.351$ & $6.300 \pm 0.384$ & $4.900 \pm 0.379$ & $4.900 \pm 0.379$ \\
\hline DSF & $6.200 \pm 0.058^{*}$ & $6.300 \pm 0.058^{*}$ & $6.367 \pm 0.033^{*}$ & $6.967 \pm 0.338^{*}$ \\
\hline CG & $7.133 \pm 0.176^{*}$ & $7.333 \pm 0.067 *$ & $7.700 \pm 0.252 *$ & $7.833 \pm 0.203^{*}$ \\
\hline $\mathrm{DSF} / \mathrm{CG}$ & $7.633 \pm 0.088^{*}$ & $7.867 \pm 0.067 *$ & $7.867 \pm 0.067 *$ & $12.60 \pm 3.754$ \\
\hline
\end{tabular}

Results are expressed as mean \pm SEM, the superscript $(*)$ means significant difference with respect to control at $\mathrm{p}<0.05$ (ANOVA).

Table 7. Effect of low dose DSF (18.65 mg/kg), CG (3.75 mg/kg) and DSF/CG $(18.65 / 3.75 \mathrm{mg} / \mathrm{kg})$ combination on urea $(\mathrm{mmol} / \mathrm{l})$.

\begin{tabular}{ccccc}
\hline & 30 Days & 45 Days & 60 Days & 90 Days \\
\hline CONTROL 1 & $16.83 \pm 0.601$ & $18.67 \pm 1.856$ & $18.33 \pm 1.667$ & $23.00 \pm 2.000$ \\
DSF & $21.33 \pm 1.764$ & $22.67 \pm 0.882$ & $23.00 \pm 0.577$ & $25.00 \pm 0.577$ \\
CG & $24.83 \pm 0.601^{*}$ & $25.17 \pm 0.441^{*}$ & $25.33 \pm 0.333^{*}$ & $25.33 \pm 0.333^{*}$ \\
DSF/CG & $26.00 \pm 0.289^{*}$ & $26.67 \pm 0.601^{*}$ & $27.00 \pm 0.866^{*}$ & $27.50 \pm 1.041^{*}$
\end{tabular}

Results are expressed as mean \pm SEM, the superscript $(*)$ means significant difference with respect to control at $\mathrm{p}<0.05$ (ANOVA).

Table 8. Effect of medium dose DSF (37.3 mg/kg), CG $(7.5 \mathrm{mg} / \mathrm{kg})$, DSF/CG (37.3/7.5 mg/kg) combination on urea $(\mathrm{mmol} / \mathrm{l})$.

\begin{tabular}{|c|c|c|c|c|}
\hline & 30 Days & 45 Days & 60 Days & 90 Days \\
\hline CONTROL 1 & $19.00 \pm 1.528$ & $19.00 \pm 1.528$ & $18.67 \pm 2.333$ & $18.33 \pm 2.186$ \\
\hline DSF & $23.67 \pm 0.333^{*}$ & $23.67 \pm 0.333^{*}$ & $25.83 \pm 0.833^{*}$ & $24.90 \pm 0.208^{*}$ \\
\hline CG & $25.33 \pm 0.333^{*}$ & $25.77 \pm 0.433^{*}$ & $25.67 \pm 0.333^{*}$ & $26.33 \pm 0.333^{*}$ \\
\hline $\mathrm{DSF} / \mathrm{CG}$ & $28.00 \pm 0.764 *$ & $28.33 \pm 0.882^{*}$ & $28.67 \pm 0.833^{*}$ & $29.33 \pm 0.167 *$ \\
\hline
\end{tabular}

Results are expressed as mean \pm SEM, the superscript $(*)$ means significant difference with respect to control at $\mathrm{p}<0.05$ (ANOVA). 
Table 9. Effect of high dose DSF (74.6 mg/kg), CG (15 mg/kg) and DSF/CG (74.6/15 mg/kg) combination on urea $(\mathrm{mmol} / \mathrm{l})$.

\begin{tabular}{|c|c|c|c|c|}
\hline & 30 Days & 45 Days & 60 Days & 90 Days \\
\hline CONTROL 1 & $18.00 \pm 2.082$ & $18.33 \pm 2.186$ & $18.33 \pm 2.186$ & $18.67 \pm 1.856$ \\
\hline DSF & $25.43 \pm 0.233^{*}$ & $26.00 \pm 0.289 *$ & $26.33 \pm 0.441^{*}$ & $26.83 \pm 0.727 *$ \\
\hline CG & $26.83 \pm 0.167 *$ & $27.00 \pm 0.289 *$ & $27.50 \pm 0.189 *$ & $27.83 \pm 0.441^{*}$ \\
\hline $\mathrm{DSF} / \mathrm{CG}$ & $29.50 \pm 0.289 *$ & $29.77 \pm 0.145^{*}$ & $30.50 \pm 0.764^{*}$ & $34.17 \pm 2.489 *$ \\
\hline
\end{tabular}

Results are expressed as mean \pm SEM, the superscript $(*)$ means significant difference with respect to control at $\mathrm{p}<0.05$ (ANOVA).

Table 10. Effect of low dose DSF (18.65 mg/kg), CG (3.75 mg/kg) and DSF/CG (18.65/3.75 mg/kg) combination on creatinine $(\mathrm{mmol} / \mathrm{l})$.

\begin{tabular}{ccccc}
\hline & 30 Days & 45 Days & 60 Days & 90 Days \\
\hline CONTROL 1 & $0.533 \pm 0.333$ & $0.667 \pm 0.067$ & $0.733 \pm 0.067$ & $0.733 \pm 0.067$ \\
DSF & $0.883 \pm 0.020^{*}$ & $0.927 \pm 0.039^{*}$ & $0.957 \pm 0.035^{*}$ & $0.977 \pm 0.003^{*}$ \\
CG & $0.927 \pm 0.019^{*}$ & $0.927 \pm 0.019^{*}$ & $0.943 \pm 0.029^{*}$ & $0.970 \pm 0.012^{*}$ \\
DSF/CG & $0.960 \pm 0.021^{*}$ & $0.963 \pm 0.023^{*}$ & $0.990 \pm 0.010^{*}$ & $1.023 \pm 0.039^{*}$ \\
\hline
\end{tabular}

Results are expressed as mean \pm SEM, the superscript $(*)$ means significant difference with respect to control at $\mathrm{p}<0.05$ (ANOVA).

Table 11. Effect of medium dose DSF (37.3 mg/kg), CG (7.5 mg/kg), DSF/CG (37.3/7.5 mg/kg) combination on creatinine (mmol/l).

\begin{tabular}{|c|c|c|c|c|}
\hline & 30 Days & 45 Days & 60 Days & 90 Days \\
\hline CONTROL 1 & $0.733 \pm 0.044$ & $0.733 \pm 0.044$ & $0.767 \pm 0.033$ & $0.700 \pm 0.577$ \\
\hline DSF & $1.017 \pm 0.042^{*}$ & $1.093 \pm 0.064^{*}$ & $1.023 \pm 0.039 *$ & $1.100 \pm 0.577^{*}$ \\
\hline CG & $1.030 \pm 0.061 *$ & $1.033 \pm 0.060 *$ & $1.033 \pm 0.060 *$ & $1.223 \pm 0.099 *$ \\
\hline $\mathrm{DSF} / \mathrm{CG}$ & $1.107 \pm 0.081^{*}$ & $1.197 \pm 0.048^{*}$ & $1.200 \pm 0.050^{*}$ & $1.250 \pm 0.050 *$ \\
\hline
\end{tabular}

Results are expressed as mean \pm SEM, the superscript $(*)$ means significant difference with respect to control at $\mathrm{p}<0.05$ (ANOVA).

Table 12. Effect of high dose DSF (74.6 mg/kg), CG (15 mg/kg) and DSF/CG (74.6/15 mg/kg) combination on creatinine $(\mathrm{mmol} / \mathrm{l})$.

\begin{tabular}{|c|c|c|c|c|}
\hline & 30 Days & 45 Days & 60 Days & 90 Days \\
\hline CONTROL 1 & $0.667 \pm 0.088$ & $0.700 \pm 0.058$ & $0.700 \pm 0.058$ & $0.700 \pm 0.058$ \\
\hline DSF & $1.183 \pm 0.044^{*}$ & $1.283 \pm 0.060 *$ & $1.467 \pm 0.033^{*}$ & $1.467 \pm 0.033^{*}$ \\
\hline CG & $1.257 \pm 0.092^{*}$ & $1.340 \pm 0.122^{*}$ & $1.417 \pm 0.164^{*}$ & $1.417 \pm 0.164^{*}$ \\
\hline $\mathrm{DSF} / \mathrm{CG}$ & $1.400 \pm 0.076^{*}$ & $1.423 \pm 0.087 *$ & $1.670 \pm 0.215^{*}$ & $2.817 \pm 0.217^{*}$ \\
\hline
\end{tabular}

Results are expressed as mean \pm SEM, the superscript $(*)$ means significant difference with respect to control at $\mathrm{p}<0.05$ (ANOVA).

$(\mathrm{Pb})$, chromium $(\mathrm{Cr})$ and platinum $(\mathrm{Pt})$ are a major environmental and occupational hazard. Unfortunately, these non-essential elements are toxic at very low doses and non-biodegradable with a very long biological half-life. Thus, exposure to heavy metals is potentially harmful. Because of its ability to reabsorb and accumulate divalent metals, the kidney is the first target organ of heavy metal toxicity. The extent of renal damage by heavy metals depends on the nature, the dose, route and duration of exposure. Both acute and chronic intoxication have been demonstrated to cause nephropathies, with various levels of severity ranging from tubular dysfunctions like acquired Fanconi syndrome to severe renal failure leading occasionally to death [17]. 


\section{Conclusion}

Disulfiram and copper gluconate as single agents are nephrotoxic as seen from our results. Administered as a combination, disulfiram/copper gluconate was nephrotoxic as shown by the development of hyperkalemia, hypernatremia, uraemia and increased creatinine levels which were higher for the drug combination when compared to the single agent. These results are pointers to the development of kidney damage in the experimental animals. The researchers believe that the nephrotoxicity observed is achieved via a synergistic toxicological effect when disulfiram and copper gluconate are combined. These effects were observed at low, medium and high doses and should therefore be used with extreme caution.

\section{Acknowledgements}

The authors are grateful to Prof. O.A. Georgewill and Dr. Dawaye A. Georgewill for their useful contributions.

\section{References}

[1] World Health Organization (2008) World Cancer Report 2008. International Agency for Research on Cancer, Lyon.

[2] Chukwuma, M. (2006) Crude Oil Pollution Raises Cancer Risk among Nigerians. African Cancer Centre.

[3] Duran-Frigola, M. and Aloy, P. (2012) Recycling Side Effects into Clinical Markers for Drug Repositioning. Genome Medicine, 4, 3. http://dx.doi.org/10.1186/gm302

[4] Li, Y.Y. and Jones, S.J. (2012). Drug Repositioning for Personalised Medicine. Genome Medicine, 4, 27.

[5] Blatt, J. and Corey, S.J. (2013) Drug Repositioning in Paediatrics and Pediatric Hematology Oncology. Drug Discovery Today, 18, 4-10. http://dx.doi.org/10.1016/j.drudis.2012.07.009

[6] Cvek, B. (2011) Targeting Malignancies with Disulfiram(antabuse); Multidrug Resistance, Angiogenesis, and Proteasome. Current Cancer Drug Targets, 11, 332-337. http://dx.doi.org/10.2174/156800911794519806

[7] Kast, R.E., Boockvar, J.A., Bruning, A., Capello, F., Chang, W.W., Cvek, B., Dou, Q.P., Duenas-Gonzalez, A., Efferth, T., Focosi, D., Ghaffari, S.H., Karpel-Massler, G., Ketola, K., Khoshnevisan, A., Keizman, D., Magne, N., Marosi, C., McDonald, K., Munoz, M., Paranjpe, A., Pourgholami, M.H., Sardi, I., Sella, A., Srivenugopal, K.S., Tucorri, M., Wang, W., Wirtz, C..R. and Halatsch, M.E. (2013) A Conceptually New Treatment Approach for Relapsed Glioblastoma; Coordinated Undermining of Survival Paths with Nine Repurposed Drugs (CUSP9) by the International Initiative for Accelerated Improvement of Glioblastoma Care. Oncotarget, 4, 502-530.

[8] Brar, S.S., Grigg, C., Wilson, K.S., Holder, W.D., Dreau, D., Austin, C., et al. (2010) Disulfiram Inhibits Activating Transcription Factor/Cyclic AMP Responsive Element Binding Protein and Human Melanoma Growth in a MetalDependent Manner in Vitro, in Mice and in a Patient with Cancer Cell Lines. Cancer Letters, 290, 104-113.

[9] Marikovsky, M., Nevo, N., Vadai, E. and Harris-Cerruti, C. (2002) Cu/Zn Superoxide Dismutase Plays a Role in Angiogenesis. International Journal of Cancer, 97, 34-41. http://dx.doi.org/10.1002/ijc.1565

[10] Cen, D., Gonzalez, R.I., Buckmeier, J.A., Kahlon, R.S., Tohidian, N.B. and Meyskens Jr, F.L. (2002) Disulfiram Induces Apoptosis in Human Melanoma Cells: A Redox-Related Process. Molecular Cancer Therapeutics, 1, 197-204.

[11] Chen, D., Cui, Q.C., Yang, H.J. and Dou, Q.P. (2006) Disulfiram, a Clinically Used Anti-Alcoholism Drug and Copper-Binding Agent, Induces Apoptotic Cell Death in Breast Cancer Cultures and Xenografts via Inhibition of the Proteasome Activity. Cancer Research, 66, 10425-10433. http://dx.doi.org/10.1158/0008-5472.CAN-06-2126

[12] Johansson, B. (1992) A Review of the Pharmacokinetics and Pharmacodynamics of Disulfiram and Its Metabolites. Acta Psychiatrica Scandinavica, 86, 15-26. http://dx.doi.org/10.1111/j.1600-0447.1992.tb03310.x

[13] Kristenson, H. (1995) How to Get the Best out of Antabuse. Alcohol and Alcoholism, 30, 775-783.

[14] Skrott, Z. and Cvek, B. (2012) Diethyldithiocarbamate Complex with Copper: The Mechanism of Action in Cancer Cells. Mini-Reviews in Medicinal Chemistry, 12, 1184-1192. http://dx.doi.org/10.2174/138955712802762068

[15] Papaioannou, M., Malonas, I., Kast, R.E. and Brüning, A. (2013) Disulfiram/Copper Causes Redox-Related Proteotoxicity and Concomitant Heat Shock Response in Ovarian Cancer Cells That Is Augmented by Auranofin-Mediated Thioredoxin Inhibition. Oncoscience, 1, 21-29.

[16] Ries, F. and Klastersky, J. (1986) Nephrotoxicity Induced by Cancer Chemotherapy with Special Emphasis on Cisplatin Toxicity. American Journal of Kidney Diseases, 8, 368-379. http://dx.doi.org/10.1016/S0272-6386(86)80112-3

[17] Barbier, O., Jacquillet, G., Tauc, M., Cougnon, M. and Poujeol, P. (2005) Effect of Heavy Metals on, and Handling by, the Kidney. Nephron Physiology, 99, 105-110. http://dx.doi.org/10.1159/000083981

[18] Owunari, G.U., Minakiri, S.I. and Wolfe, O.A. (2015) Effect of Disulfiram/Copper Gluconate Combination on Haematological Indices in Rodents. Pharmacology \& Pharmacy, 6, 17-24. http://dx.doi.org/10.4236/pp.2015.61003 
[19] Grossmann, K.F., Blankenship, M.B., Akerley, W., Terrazas, M.C., Kosak, K.M., Boucher, K.M., Buys, S.S., Jones, K., Werner, T.L., Agarwal, N., Weis, J., Sharma, S., Ward, J. and Shami, P.J. (2011) Abstract 1308: A Phase I Clinical Study Investigating Disulfiram and Copper Gluconate in Patients with Advanced Treatment-Refractory Solid Tumors Involving the Liver. Cancer Research, 71, 1308. http://dx.doi.org/10.1158/1538-7445.AM2011-1308

[20] Olurishe, T.O., Kwanashie, H.O., Anukar, J.A., Muktar, H. and Sambo, J.S. (2013) Renal Impact of Subacute Lamivudine-Artesunate Treatment in Wistar Rats. African Journal of Pharmacology and Therapeutics, 2, 48-53.

[21] Eaton, D.C. and Pooler, J.P. (2009) Vander’s Renal Physiology. 7th Edition, Lange Medical Books/McGraw-Hill, Medical Pub. Division, New York.

[22] Traynor, J., Mactier, R., Geddes, C.C. and Fox, J.G. (2006) How to Measure Renal Function in Clinical Practice. British Medical Journal, 333, 733-737. http://dx.doi.org/10.1136/bmj.38975.390370.7C

[23] Allen, P.J. (2012) Creatine Metabolism and Psychiatric Disorders: Does Creatine Supplementation Have Therapeutic Value? Neuroscience \& Biobehavioral Reviews, 36, 1442-1462. http://dx.doi.org/10.1016/j.neubiorev.2012.03.005

[24] Gross, J.L., de Azevedo, M.J., Silveiro, S.P., Canani, L.H., Caramori, M.L. and Zelmanovitz, T. (2005) Diabetic Nephropathy: Diagnosis, Prevention, and Treatment. Diabetes Care, 28, 164-176. http://dx.doi.org/10.2337/diacare.28.1.164 
Scientific Research Publishing (SCIRP) is one of the largest Open Access journal publishers. It is currently publishing more than 200 open access, online, peer-reviewed journals covering a wide range of academic disciplines. SCIRP serves the worldwide academic communities and contributes to the progress and application of science with its publication.

Other selected journals from SCIRP are listed as below. Submit your manuscript to us via either submit@scirp.org or Online Submission Portal.
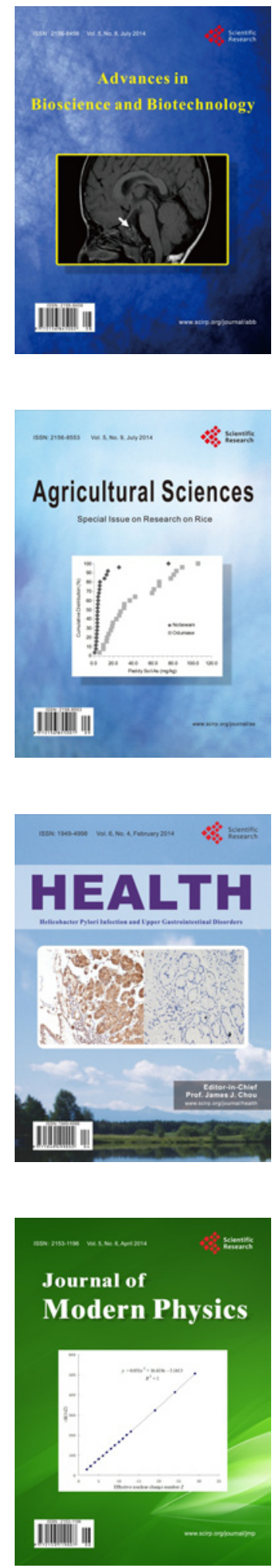
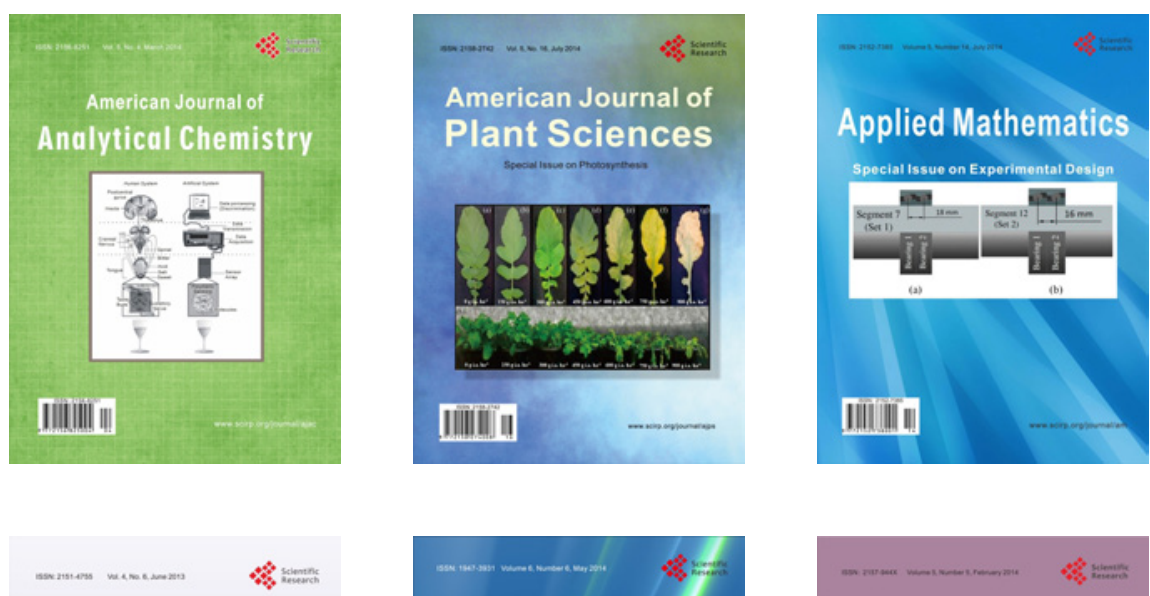

Creative Education
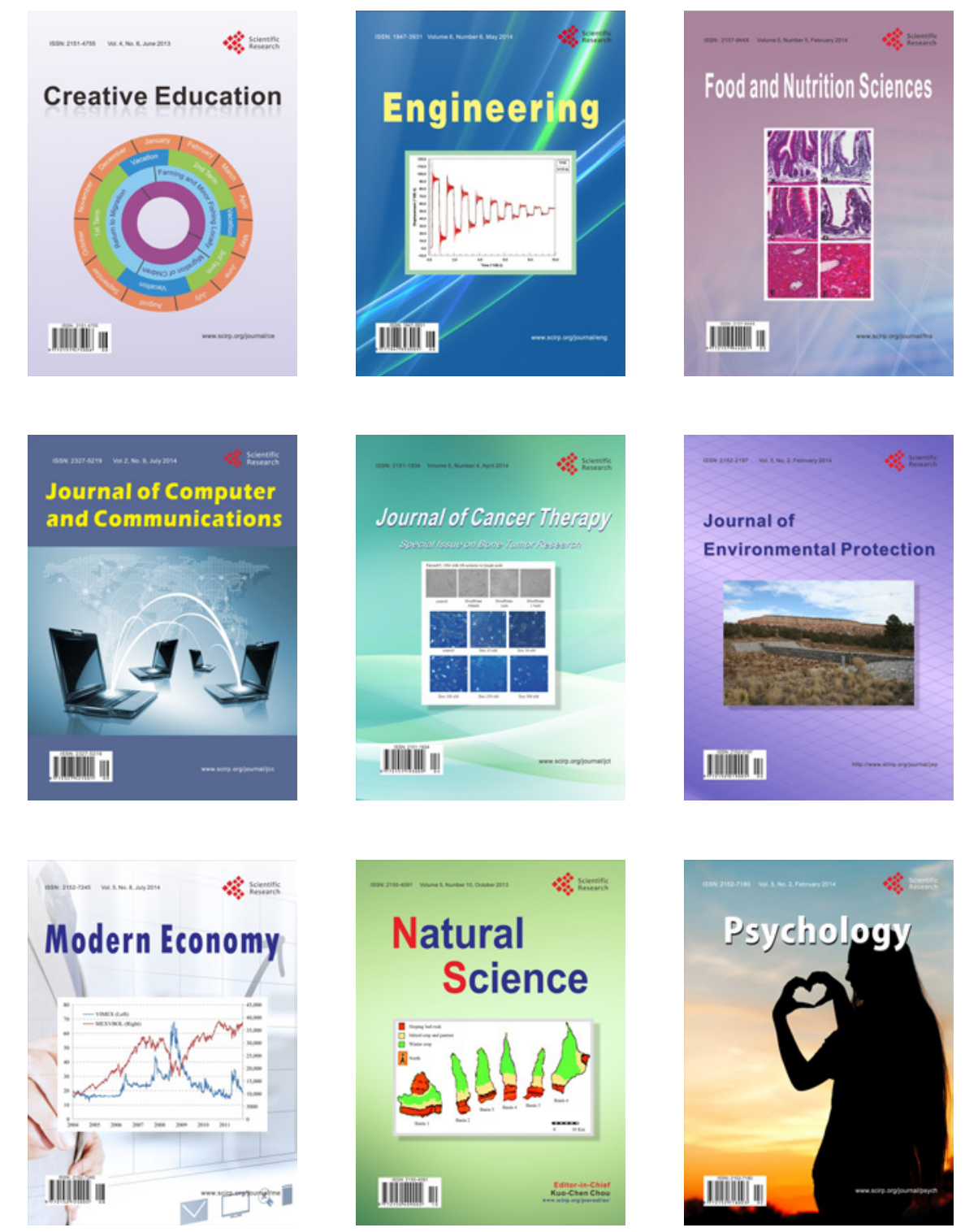